\title{
Packaging/fatty food interactions
}

Oléagineux, Corps Gras, Lipides. Volume 7, Numéro 5, 427-30, Septembre - Octobre 2000, Dossier : Sécurité sanitaire des aliments et industrie

Auteur(s) : Stéphane DESOBRY, Laboratoire de physico-chimie et génie alimentaire, École nationale supérieure d'agronomie et d'industries alimentaires (ENSAIA), Institut national polytechnique de Lorraine (INPL), 2, avenue de la Forêt-de-Haye, 54500 Vandœuvre-lès-Nancy, France.

Summary: Les contaminants résiduels ou les micro-organismes présents dans les emballages industriels peuvent migrer dans les aliments et les altérer. Les améliorations techniques et la meilleure connaissance des matériaux d'emballage permettront bientôt de voir disparaître la contamination microbiologique des emballages. Le principal problème sécuritaire concerne la migration moléculaire de composés de l'emballage vers l'aliment gras en raison de l'affinité importante des principaux contaminants pour les milieux hydrophobes. De plus, la matière grasse interagit souvent avec les emballages hydrophobes, pénètre dans le matériau et accélère la migration. Les perméabilités de l'emballage à l'oxygène et à la vapeur d'eau doivent être strictement contrôlées pour préserver les qualités nutritionnelles et organoleptiques des aliments gras. Les interactions entre l'eau et l'emballage modifient les perméabilités ce qui implique que les mesures de perméabilités doivent être réalisées dans les conditions réelles d'utilisation des emballages. Toutes ces interactions entre aliment et emballage font l'objet d'une attention soutenue et seront étudiées durant les dix prochaines années pour parvenir à leur maîtrise.

Keywords : aliment gras, contaminants, perméabilité, diffusivité, migration.

\section{ARTICLE}

When a packaging material comes into contact with food, interactions occur immediately. Interactions can act to enhance to food preservation (oxygen, $\mathrm{CO}_{2}$ or water transport) but can also alter food safety if there is migration of micro-organisms or certain chemical compounds. Microbiological contamination of food via the wrapping material has been widely studied at both European and French levels. Contamination problem are likely to be resolved within a few years.

Chemical contamination is now a major problem because of the large number of additives and the variety of packaging materials used to protect foods effective. This contamination is particularly important for hydrophobic foods such as butter, oils, fats, etc., because of the high affinity between contaminant molecules and fats.

Mass transfer within food/packaging systems has been well documented. Several authors have evaluated the migration of packaging film components in to foods where there is a direct contact between food and packaging material [1-9]. If there is no contact between food and packaging or in the case of solid foods, only volatile molecules can migrate. Volatile molecules evaporate at the packaging surface, migrate through the air, cross the air/food interface and diffuse into the food. In the case of fatty foods, their liquid or viscous composition, and their affinity with most contaminants activate migration and increase the risk of compromised food safety. 
The first part of the present article deals with this issue.

In addition to food safety, food/packaging interactions can modify the shelf-life and the quality of the food product, especially in the case of fatty foods. This will be evaluated in the second part of this paper.

The objective of this paper is to give an overview of fatty food/packaging interactions and to present the major research trends for the future.

\section{Packaging and fatty food safety}

\section{Regulation}

One of the major concerns in food safety is the molecular migration from packaging material to food during storage. Migration depends on the molecule concentration in packaging, the molecule partitioning coefficient "packaging material/food", mobility and time [10].

Several mathematical models have been used to predict the migration of constituents from packaging materials to foods during storage and/or processing. Differential equations governing mass transfer have been devised for simple boundary conditions and geometries [11], while numerical methods are used for more complex conditions, with the help of a computer $[8,12,13]$. The finite difference method has been used to solve the differential equations governing mass transfer as Hsu [14] and Bakshi and Singh [15] did for moisture gain/loss from spherical foods. The same approaches were applied by Mousavi et al. [9] to model contaminant transport from packaging to spherical food.

Because of the toxicological risk linked to migration, the EU has established several directives which are published in the EU's Official Journal for all packaging materials. These directives can be consulted on the Web at the following address: http://cpf.jrc.it/webpack. The French texts can be obtained in the "brochure 1227 du Journal officiel" entitled "Matériaux au contact des denrées alimentaires, produits de nettoyage de ces derniers".

Two of these directives (89/109 and 85/572) concern food/packaging interactions and global molecular migration. The global migration limit (GML) from packaging to food is $10 \mathrm{mg} / \mathrm{dm}$ or $60 \mathrm{mg}$ per $\mathrm{kg}$ (50mg per kg of food in the US).

In addition to these directives, some specific decisions have been adopted for each material depending on the toxicity of the material. The specific migration limit $(S M L)$ is defined for each molecule included in the packaging material. For instance, as regards metal packaging, the specific migration limit of stain is $25 \mathrm{mg} / \mathrm{kg}$, while that of aluminium is $0.2 \mathrm{mg} / \mathrm{kg}$. Directives $83 / 221$ and $83 / 338$ give the migration limit from vegetable parchment, while directive $90 / 128$ concerns plastic packaging materials.

To evaluate the potential risk of migration from packaging to foods, simulated foods were chosen to facilitate measurement of contaminant migration. These simulated foods were water, olive oil, acetic acid 3\% and ethanol 12\%. In France, the following equation is used to estimate the risk to the consumer of eating packaging contaminants, assuming that the people eat $1 \mathrm{~kg}$ of food per day including $20 \%$ of fats.

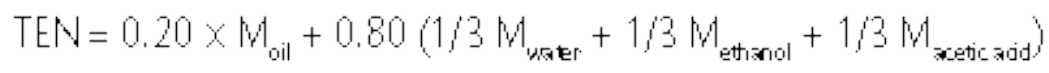

The theoretical exposure level (TEN) is compared to the maximum quantity of molecule that a consumer could eat each day without any toxicological problem. If the TEN is greater than this value, the migration is not acceptable and the food product cannot be recommanded as fit for consumption. The three safety amount (TEN, SML, and GML) will be carefully checked by official organizations to ensure food safety. 


\section{Diffusivity, solubility and contamination rate}

The rate of contamination of food by mobile packaging molecules depends largely upon the diffusivity (D) of the molecules. The apparent diffusivity is needed to determine the time taken by the molecule to achieve the specific migration limit into food. Generally, molecular mobility is lower in packaging than in food.

The other parameter essential for evaluating the risk of migration is the solubility (S) of the contaminant molecule. This gives the affinity of the molecule for food or for packaging. If the molecule has a high affinity for the packaging, migration will be low but, if the molecule has a high affinity for the food, transport will be fast and the specific migration limit must be checked carefully.

In the case of fatty foods, fats often penetrate the packaging material because of their high hydrophobicity. This penetration activates the migration, and contaminants present in the packaging are rapidly extracted and migrate to the food. This high interaction has to be carefully evaluated to avoid risk to the consumer.

Temperature activates the diffusivity and then migration as in any other physico-chemical reaction. The temperature effect has been modelled by several authors. The models most used are those of Arrhenius and of William, Landel and Ferry.

$$
\text { Arrhenius model: } \mathrm{D}=\mathrm{D}_{0} \exp \left(\frac{-\mathrm{Ea}}{\mathrm{RT}}\right)
$$

WLF model: $\log \left(\frac{Q_{(T)}}{D\left(T_{\text {Ref }}\right)}\right)=\frac{\left.-C_{1} T-T_{\text {Ref }}\right)}{C_{2}+\left(T-T_{\text {Ref }}\right)}$

Both models give the diffusion rate at a given storage temperature, every other parameter being unchanged. The diffusion rate at temperature $T$, noted $D(T)$, is simply a function of constants such as $D_{0}$ or $D\left(T_{\text {Ref }}\right)$, diffusion rates at reference temperatures $T_{0}$ and $T_{\text {Ref, }}$ activation energy, $E_{a}$ and constants, $C_{1}$ and $C_{2}$. William et al. proposed the use of $C_{1}=17.4$ and $C_{2}=51.6$, but it is important to check these values before using the model.

The molecular mass of the contaminant has a great effect on the diffusion rate. The larger the migrant molecule, the lower the diffusivity. Moreover, diffusivity is highly sensitive to migrant concentration. The higher the concentration, the lower the diffusivity.

\section{Fatty food quality controlled by packaging}

\section{Gas transport}

Oxygen has a deleterious effect on fatty foods. The shelf-life of these products is very often directly linked to oxidation. Packaging has to then protect the food from oxygen transfer from the environment to the food. The oxygen permeability is a very important property of the packaging and has to be as low as possible. As permeability is linked to the diffusivity and the solubility of the oxygen molecule in the packaging material, good packaging materials for fats have to present very few adsorption sites for the oxygen, in their macromolecular structure. Moreover, the number of pores in the film reduces the interest of using high barrier materials because it was recently demonstrated that even a few pores in packaging materials have a dramatic impact on gas transport. Indeed, most of the oxygen transport take place through those holes. 


\section{Light transmittance}

Light is an important oxidation activator. Partial or total absorption of UV and visible spectra has to be a priority to efficiently protect the fatty food from oxidation : three percent of transmittance was demonstrated to be the maximum value acceptable to ensure good protection against oxidation.

\section{Water diffusion}

In the case of butter or margarine, water loss through packaging leads to surface dehydration and increases surface yellowness, which is often considered by the consumer as a decrease of the quality of the product. Water diffusion in packaging has to be carefully controlled.

In the case of Brie or Camembert cheese ( $45 \%$ to $60 \%$ fats), the packaging material is much more difficult to optimize. Stopping exchange between the environment and the cheese is not possible if the surface flora are to be kept alive. Excess water in contact with the flora leads to alteration of appearence and the product is unacceptable to consumers. Absorption of the water desorbed by the cheese, transport through the packaging and desorption from the packaging to the environment has to be optimized to limit weight loss and maintain the requirements of the cheese flora.

Water desorption from a packaged cheese occurs in two phases: a swelling phase, which begins when the packaging first comes into contact with the cheese, and a steady phase, when all packaging absorbent sites are saturated and the rate of water desorption is constant (figure 1). Each phase has to be perfectly controlled to ensure good preservation and minimum weight loss.

\section{Combined water and gas transport}

Gas transport through packaging film is one of the most important parameters influencing the shelflife of fatty foods. Its control is necessary for the industrial development of controlled atmosphere packaging materials and systems [16]. The current standard measurement method (ISO 2556) is not suitable for hydrated packaging because measurements, made at $23^{\circ} \mathrm{C}$ and $0 \%$ or $50 \% \mathrm{RH}$, are far removed from conditions used in industry (60\% to $97 \% \mathrm{RH})$ and often cannot be used to measure gas ex-changes during real food storage. In a recent paper, Desobry and Hardy [17] studied $\mathrm{CO}_{2}$ transport through hydrated paper using gas chromatography to measure $\mathrm{CO}_{2}$ permeability $(\mathrm{P})$ and diffusivity (D). The cell used for permeability measurement for any water activity is presented in the figure 2 .

With increasing water content from 0 to $0.8 \mathrm{~g}_{\text {water }} / \mathrm{g}_{\text {paper }}$, from figure 3 , and applying Fick and Henry's laws, it was found that $P$ and $D$ increased from 3.47 to $9.03 \times 10^{-6} \mathrm{~m}^{3} \cdot \mathrm{m}^{-2} \cdot \mathrm{s}^{-1}$. bar ${ }^{-1}$ and from 1.35 to $3.51 \times 10^{-5} \mathrm{~m}^{2} \cdot \mathrm{s}^{-1}$ respectively. This resulted from structural changes in the cellulose network, as reported in the literature.

Indeed, hydration leads to internal forces being generated and the cellulose network swelling. Molecular mobility is increased and mass transfer becomes faster. Permeability multiplies three when the paper packaging is hydrated.

$$
P=-D \frac{d C}{d x}\left(\frac{1}{\Delta p}\right)
$$

\section{CONCLUSION}

The research presented in this paper will be the main focus for development over the next ten years. Today, to anyone studying food/packaging interactions in terms of quality and safety, food safety is certainly of major concern in the most developed countries while food quality preservation is the main objective in poorer countries.

Interactions between packaging and fatty foods are numerous because of the high hydrophobicity of the plastic of packaging materials. The aim of butter, margarine, and oil producers will be to limit these interactions and particularly the absorption of fats into the packaging material. 


\section{REFERENCES}

1. CHANG S, GUTTMAN CM, SANCHEZ IC, SMITH LE (1988). Theoretical and computational aspects of migration of packaging components to food. Chap. 9. Washington D.C.: American Chemical Society.

2. MERCER A, CASTLE L, COMYN J (1991). Evaluation of a predictive mathematical model of di-(2ethylhexyl) adipate plastisizer migrant from PVC film into foods. Food Additives and Contaminants: 497-507.

3. GORDON M (1990). Principles and applications of gas chromatography in food analysis. Ellis Ser Food Sci Technol: 89-109.

4. BEGLY TH, HOLLIFIELD HC (1990). Evaluation of polyethylene tetraphthalate cyclic migration from microwave food packaging using temperature-time profiles. Food Add Contam, 7: 339-46.

5. DENIS PAGE B, LACROIX GM (1992). Studies into the transfer and migration of phthalate esters from aluminium foil paper laminates to butter and margarine. Food Add Contam, 9: 197-212.

6. CASTLE L, KELLY M, GILBERT J (1993). Migration of mineral hydrocarbons into foods. 2. Polystyrene, ABS and waxed paperboard containers for dairy products. Food Add Contam, 10 : 167-74.

7. DESOBRY S, HARDY J (1994). Camembert cheese water loss through absorbent packaging. J Food Sci, 59: 986-89.

8. MOUSAVI M, DESOBRY S, HARDY J (1998). Mathematical modelling of acetic acid migration from packaging into food via package free space. Part I - spherical shape foods. J Food Eng, 36: 453-72.

9. MOUSAVI M, DESOBRY S, HARDY J (1998). Mathematical modelling of acetic acid migration from packaging into food via package free space. Part II - cylindrical shape foods. J Food Eng, 36: 473-84.

10. GILBERT SG (1976). Migration of minor constituents from food packaging materials. J Food Sci, 41: 955-8.

11. CRANK J (1975). The mathematics of diffusion. Oxford: Clarendon Press.

12. CROFT DR, LILLEY GD (1977). Heat transfer calculations using finite difference equations. London: Applied Science Publishers.

13. LAUMARO GL, BAKSHI AS (1985). Finite element analysis of moisture diffusion in stored foods. J Food Sci, 50: 392-6.

14. HSU KH (1983). A diffusion model with a concentration-dependent diffusion coefficient for describing water movement in legumes during soaking. J Food Sci, 48: 618-22.

15. BAKSHI AS, SINGH RP (1980). Kinetics of water diffusion and starch gelatinization during rice parboiling. J Food Sci, 45: 1387-92.

16. ILTER M, OZILGEN M, OBBEY N (1991). Modelling permeation of modified atmosphere gas mixtures through 1d polyethylene package film. Polymer International, 25: 211-7.

17. DESOBRY S, HARDY J (1997). The increase of $\mathrm{CO}_{2}$ permeability with paper hydration. Int J Food Sci Technol, 32: 407-411. 
Illustrations

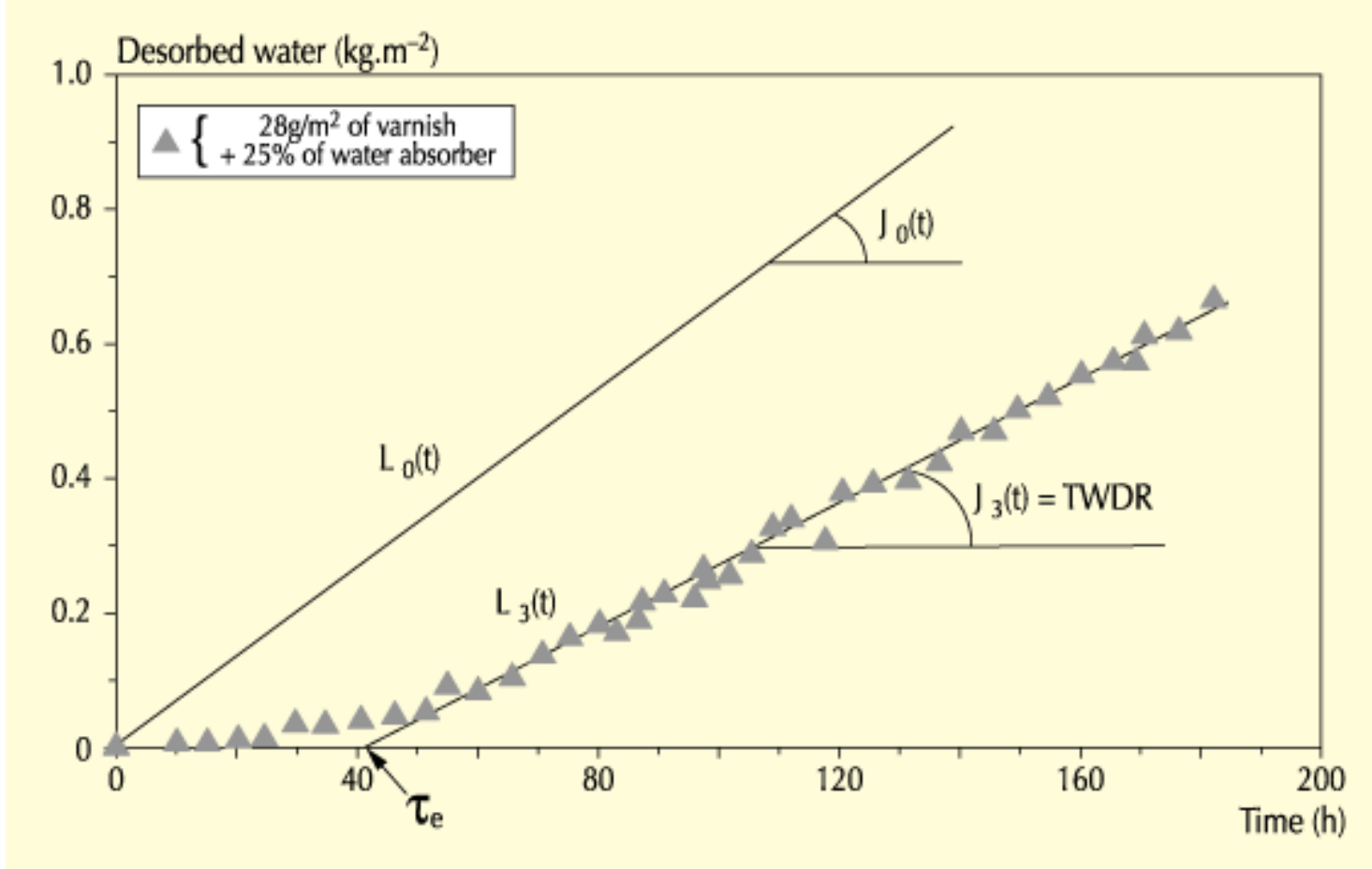

Figure 1. Weight loss and total water desorption rate from a simulated food (agar gel) ( $L_{0}$ and $J_{0}$ ) and from a soft cheese, wrapped in a three-layer packaging containing water absorber $\left(L_{3}\right.$ and $\left.J_{3}\right)$ at $10^{\circ} \mathrm{C}$ and $75 \%$ humidity. théta $a_{e}$ is the hydration time lag. 


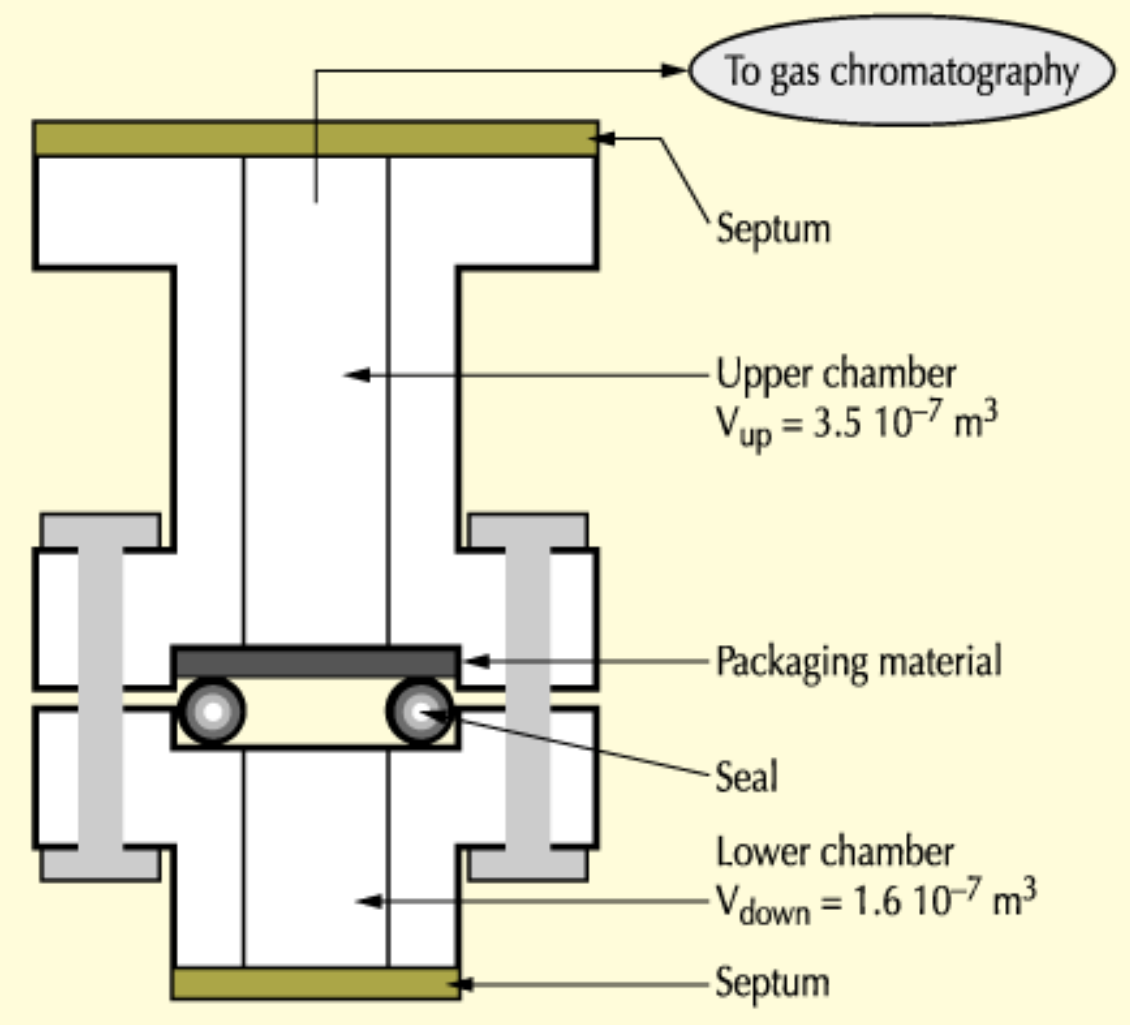

Figure 2. Experimental set-up for contaminant diffusivity and permeability measurements.

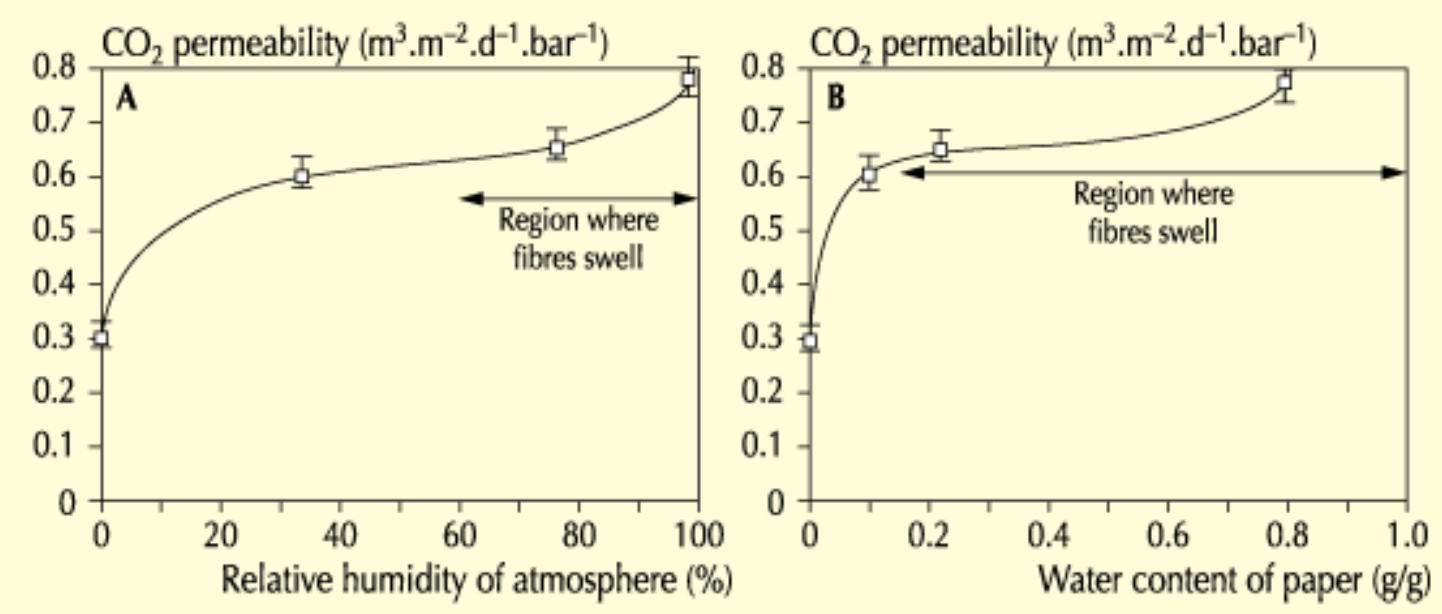

Figure 3. $\mathrm{CO}_{2}$ permeability versus relative humidity (a) and water content (b) of a paper packaging. 